\title{
Contribution of Neuro-Imaging for Prediction of Functional Recovery after Ischemic Stroke
}

\author{
Wolf-Dieter Heiss \\ Max Planck Institute for Metabolism Research, Cologne, Germany
}

\begin{abstract}
Keywords
Imaging · Stroke · Recovery · Computed tomography · Magnetic resonance imaging $\cdot$ Positron emission tomography · Diffusion tensor imaging
\end{abstract}

\begin{abstract}
Prediction measures of recovery and outcome after stroke perform with only modest levels of accuracy if based only on clinical data. Prediction scores can be improved by including morphologic imaging data, where size, location, and development of the ischemic lesion is best documented by magnetic resonance imaging. In addition to the primary lesion, the involvement of fiber tracts contributes to prognosis, and consequently the use of diffusion tensor imaging (DTI) to assess primary and secondary pathways improves the prediction of outcome and of therapeutic effects. The recovery of ischemic tissue and the progression of damage are dependent on the quality of blood supply. Therefore, the status of the supplying arteries and of the collateral flow is not only crucial for determining eligibility for acute interventions, but also has an impact on the potential to integrate areas surrounding the lesion that are not typically part of a functional network into the recovery process. The changes in these functional networks after a localized lesion are assessed by functional imaging methods, which additionally show altered pathways and activated secondary centers related to
\end{abstract}

\section{KARGER}

๑) 2017 S. Karger AG, Basel

E-Mail karger@karger.com

www.karger.com/ced residual functions and demonstrate changes in activation patterns within these networks with improved performance. These strategies in some instances record activation in secondary centers of a network, for example, also in homolog contralateral areas, which might be inhibitory to the recovery of primary centers. Such findings might have therapeutic consequences, for example, image-guided inhibitory stimulation of these areas. In the future, a combination of morphological imaging including DTI of fiber tracts and activation studies during specific tasks might yield the best information on residual function, reserve capacity, and prospects for recovery after ischemic stroke.

(c) 2017 S. Karger AG, Basel

\section{Introduction}

Stroke is a major global health problem and a leading cause of long-term adult disability worldwide. Despite a statistically significant reduction in the rates of incidence, mortality, and disability-adjusted life years from 1990 to 2013, the absolute number of people affected by stroke has increased significantly [1]. Only a small proportion of stroke survivors (approximately 14\%) achieve full recovery of activities of daily living, while $25-50 \%$ require some assistance, and approximately half experience long-term dependency [2]. As a consequence, the absolute number 
of disability-adjusted life years due to ischemic stroke (more than 47 millions) is dramatically high. Additionally, stroke should no longer be regarded as a disease of the elderly, as two-thirds of all stroke occur among persons of age below 70 years.

With stroke, the life of an individual undergoes a complete change - and the quality of life is significantly affected by decisions made in the initial period. One decision - which has to be made without delay due to the progress of brain damage with the duration of ischemia [3] - is on the acute treatment, and must be based on an estimation of efficacy of therapeutic strategies available and possible in a single case. According to common guidelines, patients with an acute cerebrovascular attack should be admitted to a specialized and adequately equipped hospital or stroke unit, where the decision on the best treatment will not only be based on clinical data [4], but also be supported by results from imaging and laboratory tests. At least one imaging study - computed tomography (CT) or magnetic resonance imaging (MRI) - is required to prove the diagnosis and rule out large morphological lesions, but simple and even complex clinical scores including morphologic imaging data require perspective studies to prove their validity for the prediction of therapeutic efficacy [5]. Since the existence of functionally impaired but morphological intact tissue is the prerequisite for the efficacy of reperfusion therapy in acute ischemia, many studies testing invasive treatment in the first hours after stroke were based on penum$\mathrm{bral} /$ mismatch imaging for recruiting patients [6-9]; however, criteria for the prediction of efficacy in individual cases were not assessed.

The aim of this review is not to describe whether the data collected from acute stroke patients are useful for the selection of an individualized treatment, but to collect evidence to establish that neuroimaging data may be helpful for the prediction of recovery and long-term outcome. This prediction should be achieved in the subacute stage 1-3 weeks after the attack and is important for informing patients and their relatives properly on realistic and attainable goals for treatment and rehabilitation, for planning of discharge, and for anticipating possible consequences for home adjustments and community support [10]. Table 1 summarizes the approaches for the prediction of outcome after ischemic stroke with stepwise increasing complexity of clinical data and addition of various imaging results.

Several systemic reviews have discussed the relationship of standardized measures to various aspects of stroke outcome and recovery, including quantification of neu-

Contribution of Neuro-Imaging for

Prediction of Functional Recovery rologic deficits, functional outcome, and quality of life $[11,12]$. A systemic review of prognostic studies [12] indicated that age and motor weakness were important predictive variables of outcome, in addition to stroke severity; however, gender and presence of vascular risk factors were not. Employing simple models, a modestly large percentage of patients could be correctly classified with respect to survival and functional recovery $(70.4-72.9 \%$ [13]), and with respect to the severity of impairment on BI (severe vs. mild neurologic deficits, AUC 0.789-0.808 depending on the time of assessment $2-5$ days, [14]). The addition of more clinical variables in a relatively simple model improved the prediction accuracy slightly $(83.9 \%$ [15]). The complex model based on an integer score from age, severity of stroke at admission by National Institute of Health Stroke Scale (NIHSS), time from stroke onset to admission, range of visual fields, acute glucose value, and level of consciousness reached an AUC of 0.850 in the original population and of 0.903 in a stroke population pooled from 3 centers [16] and was superior to the prediction by experienced physicians ( 3 months mRS: 286.5 vs. $56.8 \%$ [17]). The changes on the NIHSS and of symptoms and signs of traditional Chinese medicine during the first 5 days after stroke predicted the 90-day outcome [18]. As motor functions and walking are in the center of rehabilitative activities, several studies concentrated on the prediction of recovery of these modalities and developed special models for this application [19-21]. Chances for improvement of post-stroke aphasia can be estimated from the performance in word repetition from a language screening task, supporting the importance of perception and motor production for recovery of language function [22]. Additionally, studies of evoked potentials are helpful to assess the potential for functional recovery and to select patients who can benefit from targeted rehabilitative procedures [23]. Recently it was also shown that the causative classification of stroke is valid for the prediction of recovery [24].

Neuroimaging is now widely available and forms a routine in the clinical work-up of stroke patients. Imaging studies provide valuable insights into the pathophysiology of stroke and the extent of injury, and have the potential to improve the accuracy of stroke outcome prediction (Table 1). However, more studies are needed to establish conclusively which biomarkers are best predictors of functional recovery after stroke [25]. Current evidence suggests that the addition of neuroimaging data to models containing clinical predictors yields clinically important increases in predictive accuracy [21]. In this review, which is an update of a previous publication [26], 
Table 1. Attempts for the prediction of outcome after ischemic stroke: application of increasingly complex clinical data and addition of results from imaging studies

\begin{tabular}{|c|c|}
\hline \multicolumn{2}{|l|}{ Clinical data } \\
\hline Individual variables & $\begin{array}{l}\text { Age, initial neurological status, arm paresis, ability to walk, prestrike } \\
\text { independence, previous stroke (Veerbeek et al. [12], 2011) }\end{array}$ \\
\hline Scores & $\begin{array}{l}\text { National Institute of Health Stroke Score (NIHSS) (Weimar et al. [120], } \\
\text { 2004, Kwakkel et al. [14], 2010) }\end{array}$ \\
\hline Indices & $\begin{array}{l}\text { Age and NIHSS (König et al. [13], 2008) } \\
\text { Barthel Index (Granger et al. [121], 1979) } \\
\text { Functional Independence Measure (Alexander et al. [122], 1994) }\end{array}$ \\
\hline Models & $\begin{array}{l}\text { - Including age, upper limb paralysis, NIHSS, urinary catheter, oxygen } \\
\text { administration (Muscari et al. [15], 2011) } \\
\text { - Including age, prestroke independence, arm paresis, ability to walk, stroke } \\
\text { severity score (Reid et al. [123], 2010) } \\
\text { - Including age, sex, prestroke disability, dysarthria, urinary incontinence, } \\
\text { limb deficit (Tilling et al. [124], 2001) }\end{array}$ \\
\hline Complex model: ASTRAL & $\begin{array}{l}\text { Age, NIHSS, time from symptom onset to admission, stroke-related visual } \\
\text { field deficit, acute blood glucose value, level of consciousness (Ntaios et al. } \\
[16], 2012)\end{array}$ \\
\hline Addition of imaging modalities* & $\begin{array}{l}\text { Volume of infarct on CT or MRI, hemorrhagic transformation or } \\
\text { intracerebral hemorrhage on CT or MRI, location and size of infarct: } \\
\text { ASPECTS } \\
\text { Dense middle cerebral artery sign on CT } \\
\text { Volume of early irreversible damage: DWI } \\
\text { Affected fiber tracts: DTI }\end{array}$ \\
\hline Addition of data on blood supply & $\begin{array}{l}\text { Vessel occlusion on angiography, CT- or MR-angiography } \\
\text { Collateral flow on CTA or MRA } \\
\text { Perfusion in tissue: pCT, PWI } \\
\text { Mismatch/penumbra: PW/DWI }\end{array}$ \\
\hline Addition of functional imaging & $\begin{array}{l}\text { fMRI at rest and during activation by specific tasks } \\
\text { PET at rest and during activation by specific tasks }\end{array}$ \\
\hline
\end{tabular}

the contributions of various neuroimaging modalities for the prediction of recovery and of functional outcome in patients after ischemic stroke and their role in assessing the efficacy of rehabilitation therapies, both in clinical trials and in individual patients, are discussed.

\section{Structural Imaging}

\section{Computed Tomography}

The routinely used imaging procedure in acute stroke is $\mathrm{CT}$, which allows differentiation between hemorrhagic and ischemic stroke, localization, and extent of the lesion, and assists in decision-making regarding the administra- tion of potentially risky stroke therapies including thrombolysis and endovascular thrombectomy. Initial infarct volume determined within $72 \mathrm{~h}$ of ischemic stroke onset was an independent predictor of outcome at 90 days, along with age and NIHSS score [27].The prognosis for stroke recovery is also related to the site of ischemic brain injury: Strokes in the insular region has been associated with increased mortality [28]. In a prospective study of patients with acute ischemic stroke, anterior choroidal infarcts were found to have an intermediate long-term prognosis between lacunar infarcts and large artery territory hemispheric infarcts [29]. Lesions located in the internal capsule demonstrated a worse prognosis for recovery of hand motor function at one year than strokes in the corona radiata 
or motor cortex [30]. Evidence of brain edema predicts poor outcome after non-lacunar ischemic stroke [31].

The Alberta Stroke Program Early Computed Tomography Score (ASPECTS) was developed to evaluate the extent and location of ischemic changes in 10 regions within the territory of the middle cerebral artery (MCA) [32]: this scale is related to functional outcome on $\mathrm{mRS}$ at 3 months post-stroke. In combination with age and severity of neurologic deficits, a subacute ASPECTS of more than 5 had a significant predictive value of greater functional independence at 3 months $\left(R^{2}=0.701\right)$ and 1 year post-stroke $\left(R^{2}=0.528\right)$ [33]. Also, the initial lesion volume was a strong and independent predictor of stroke outcome in a statistical regression model that also accounts for age and NIHSS [27]. As a consequence, the inclusion of lesion size in predictive models of outcome has the potential to improve stratification of samples and increase the power for effective detection in trials of acute therapies and of rehabilitative strategies in ischemic stroke. The evaluation of stroke volume and localization when combined with NIHSS showed potential predictive value, which might be further improved by several biomarkers, namely the S100 calcium-binding protein B, $\mathrm{C}$-reactive protein, matrix metalloproteinases, and cerebral natriuretic peptide [34].

The predictive value of complex clinical models, such as ASTRAL [16], can be improved by the addition of dense MCA sign from CT [35]). This score could predict the outcome after thrombolysis with high accuracy (AVC $0.84)$, and was better than the prediction by experienced physicians (mRS5-6 at 3 months: 80.4 vs. $40.4 \%$ [17]).

\section{Magnetic Resonance Imaging}

High resolution structural MRI sequences identify even small stroke lesions, but relating the size of lesions to clinical impairment and functional outcome is difficult, especially since small lesions of the subcortical white matter or the brainstem can produce disproportionate clinical disturbances [36]. Therefore, lesion location also needs to be considered. Involvement of the corticospinal tract by the ischemic lesion is a particularly important factor, limiting the upper limb motor recovery [37], while the impact on gait is less pronounced [38]. Severe white matter disease may also be an independent predictor of poor functional outcome [39].

Hemorrhagic transformation (HT), visualized on non-contrast CT or T2*-weighted MRI sequences is a biomarker of potentially poor outcome. Gradient Echo Sequences MRI is significantly more sensitive to HT than CT or other MRI sequences [40]. Rating scales incorpo-

Contribution of Neuro-Imaging for

Prediction of Functional Recovery

rating the extent of hemorrhage along with measures of neurologic deterioration have shown that the presence of $\mathrm{HT}$, particularly when considered "symptomatic ICH", is predictive of poor functional outcome. However, compared to other predictive factors, the contribution of symptomatic ICH may be smaller [41]. Of interest, even "asymptomatic HT" appears to be a predictor of poor outcome [42].

Diffusion-weighted imaging (DWI) provides an early, distinct, and sensitive measure of both the size and location of ischemic brain lesions. In patients with non-lacunar strokes in the anterior circulation, lesion volume assessed by DWI in addition to age and NIHSS score was an independent predictor of outcome, separating patients with a final BI above or below 85 [43]. DWI lesion volume significantly increased the power of some, but not all [44] prediction models; however, this effect was not large enough to be clinically significant in other analysis [45]. The likelihood of achieving excellent neurological outcome diminished substantially with the growth in DWI infarct volume in the first 5 days after ischemic stroke of mild-to-moderate severity [46]. Some studies have incorporated information on infarct location to predict neurologic deficits $[47,48]$.

Diffusion tensor imaging (DTI) permits visualization of white matter pathways in the brain and has been specifically used to demonstrate damage to the corticospinal tract, which is commonly associated with motor impairment in chronic stroke patients [49]. DTI measures may also be used to predict long-term outcome (30). The initial fiber number ratio calculated for the affected corticospinal tract normalized to the contralateral unaffected side predicted motor outcome after 1 year; in a multivariate anal$y$ sis, the initial fiber number ratio was an independent predictor of motor outcome ( $p=0.031$ ), improving the prediction compared with using only initial Fugl-Meyer score, age, and stroke volume $(p=0.026)$ [50]. DTI lesions visible within 3 weeks after stroke were associated with motor deficits at 3 months in supratentorial stroke patients with severe motor involvement [51]. In one study, the extent of damage to the corticospinal tract following a corona radiata infarct assessed 7-30 days after a stroke was related to the motor function of the affected hand 6 months later $[52,53]$. The damage to the pyramidal tract assessed by fractional anisotropy (FA) in DTI progressively decreased in the medulla as well as in proximal portions 1-12 weeks after pontine infarction, and these anterograde and retrograde degenerations were accompanied by deterioration in the clinical scales of motor function [54]. The prediction of motor impairment and recovery was

Cerebrovasc Dis 2017;44:266-276 
improved; not only the pyramidal tract, but also the alternative motor fibers were included in the classification of damage [37]. Damage to the posterior limb of the internal capsule within $12 \mathrm{~h}$ of symptom onset correlated well with motor impairment at 30-90 days; the sensitivity and specificity of the DTI parameters were superior to lesion volume in the corona radiata or the cortex and to baseline clinical scores [55]. A random effects model developed on the results from 11 selected studies revealed that the DTI parameter FA is a significant predictor of upper limb motor recovery after ischemic stroke [56].

Efficiency of rehabilitative therapy has been related to DTI parameters of individual tracts and tract combinations, and may indicate a patient's individual recovery potential and the optimal rehabilitative intervention [57]. Additionally, gains from treatment were related to the degree of injury to specific motor tracts (descending from primary motor cortex, supplementary motor area, dorsal premotor cortex, and ventral premotor cortex, respectively), and the damage to these tracts had a greater impact on the therapeutic effect than the infarct volume or baseline clinical status [58].

The effect of brain computer interface technology in rehabilitation strategies on upper-limb motor activities could be related to DTI measures of the posterior limb of the internal capsule (FA, axial, radial, and mean diffusivity): lower diffusivity and higher FA values measured immediately and 1 month after interventions were significantly correlated to motor outcomes [59].

Non-motor pathways can also be studied by relating their damage to higher brain function, for example, language performance. Lower FA values in the superior longitudinal and arcuate fasciculi of the left hemisphere were correlated with decreased ability to repeat spoken language, and lower FA values in the arcuate fasciculus were associated with comprehension deficits; these relationships were independent of the degree of damage to cortical areas [60]. The outcome of aphasia was improved in patients whose left FA could be reconstructed [61].

All these data stress that the connectivity in networks, as assessed by DTI, is likely to be more important for outcome and recovery than the extent of the primary structural lesion. However, despite all these promising results, structural neuroimaging neither provides information on the cause of the ischemic lesion and compensatory mechanisms, nor indicates whether or how surviving tissues are working [62]. The individual markers for structural integrity - CT, MRI, and DTI - are not sufficient to reliably predict post-stroke recovery. Their validity might be improved by adding functional biomarkers, for example, functional MRI and transcranial magnetic stimulation, in a combination of biomarkers [25]. The functional connectivity between cortical and subcortical components of neural networks determines the capacity for reorganization and recovery. The studies of these measures require modalities for physiologic, molecular, and functional imaging.

\section{Assessment of Brain Blood Supply and Cerebral Perfusion}

The reduction of regional cerebral blood flow below a critical threshold for a critical period of time causes ischemic tissue damage. This critical situation is usually triggered by the occlusion of the feeding vessel and the insufficiency of collateral perfusion. Occlusion of a large intracranial vessel, such as the basilar, internal carotid, or MCA, is associated with higher mortality and more severe permanent deficits, and therefore contributes predictive value to models of stroke outcome $[63,64]$. Basilar and internal carotid artery occlusions detected by conventional angiography has the highest NIHSS scores [65] and the worst outcome [66], whereas normal angiograms predicted a good prognosis. Large vessel occlusion detected by CT angiography (CTA) in the first $24 \mathrm{~h}$ after the attack significantly increased the 6-month mortality (4.5fold increase), and was negatively correlated to good outcome (mRS $\leq$ two-threefold reduction) [67]. Basilar and internal carotid occlusions independently affected the outcome in addition to age and NIHSS. Information from CT angiography contributed significantly to outcome prediction than the ASPECTS score $[68,69]$. Stroke outcome prediction was improved when CTA results were combined with the NIHSS (STOP Stroke study [68]).

The final size of an infarct is not only influenced by the occluded vessel, but also by the extent and quality of collateral circulation to the affected brain area. Conventional angiography can demonstrate robust collateral flow, which has been linked to reduced infarct volumes; in cases receiving thrombolysis, collateralization was a significant univariate predictor in addition to occlusion type and recanalization $[70,71]$. Rapid recruitment of sufficient leptomeningeal collaterals, as assessed by CTA, was related to favorable outcome, whereas patients with diminished sylvian and leptomeningeal collaterals had a greater risk of worsening [72]. Univariate analysis identified the grade of leptomeningeal vascularity as an independent predictor of good outcome [73]. Early CTP ASPECTS leptomeningeal collaterals in the M5 (parietal) region were independently associated with good functional outcome; when M5 collaterals score was added to 
the NIHSS, a better prediction value was achieved (area under the curve: $0.752, p<0.001$ ) [74].

For perfusion parameters obtained by CT or MRI, a weak relationship of PWI lesion size early after the ictus [75] as well as perfusion CT-mismatch [76] and mRS score 3 months after the stroke was obtained, confirming early results of the relationship between cerebral blood flow measured with 133 xenon [77] or with $99 \mathrm{~m}$ Technetiumlabeled hexamethyl propylene amine [78] and final outcome. Several studies have suggested that ASPECTS applied to CTP is more accurate in predicting outcome compared to NCCT ASPECTS [79, 80]. Location-weighted CTP analysis may be a valuable tool for predicting motor improvement and language improvement $[81,82]$. For multimodal MRI, addition of both DWI and MTT lesion volumes to NIHSS information is superior to NIHSS alone in predicting outcomes $[83,84]$. In one study, it was found that the cerebral blood volume defined by CTP ASPECTS was the best predictor of clinical outcome in acute ischemic stroke as it recognizes the infarct; it was better than CTP mismatch implying that the extent of the core is the main determinant of outcome, irrespective of the penumbra site [85]. CBV-ASPECTS was also a significant predictor of clinical outcome in patients with acute ischemic stroke treated with mechanical thrombectomy [86].

Penumbral imaging and its role in selecting patients for reperfusion therapies is discussed in a recent review [87]. However, a number of prediction scores have been developed and applied in cohorts undergoing reperfusion therapies. The effect of therapy with rtPA was related to clinical data and findings in imaging [88], and a special combined score (DRAGON) could predict poor and good outcome (AUC $0.82-0.84$ respectively) $[89,90]$. A 5 -item scale including infarct volume was able to predict the outcome after iv-tPA treatment in the DEFUSE cohort with $83 \%$ sensitivity and $86 \%$ specificity [91]. Reperfusion demonstrated on perfusion weighted-MRI was associated with good clinical outcome [92-95]. Even late reperfusion seen in PWI after embolectomy predicted improved outcome [6]. A score combining age, glucose, NIHSS, and ASPECTS of $\geq 5$ predicted poor outcome after intra-arterial therapy [96].

\section{Role of Functional Imaging in Stroke Patients}

The functional deficit after a focal brain lesion is determined by the localization and the extent of tissue damage; recovery depends on the adaptive plasticity of the undamaged brain, especially the cerebral cortex, and of the nonaffected elements of the functional network. Since destroyed tissue usually cannot be replaced in the adult hu-

Contribution of Neuro-Imaging for

Prediction of Functional Recovery man brain, improvement, or recovery of neurological deficits can be achieved only by the reactivation of functionally disturbed but morphologically preserved areas or by recruitment of alternative pathways within the functional network. This activation of alternative pathways may be accompanied by the development of different strategies to deal with the new functional-anatomical situation at the behavioral level. Additionally, the sprouting of fibers from surviving neurons and the formation of new synapses could play a role in long-term recovery. These compensatory mechanisms are expressed in altered patterns of blood flow or metabolism at rest and during activation within the functional network involved in a special task, and therefore functional imaging tools can be applied successfully for studying physiological correlates of plasticity and recovery noninvasively after localized brain damage. The observed patterns depend on the site, extent, and also on the type and dynamics of the development of the lesion; they change over time and hence are related to the course and recovery of a deficit. The visualization of disturbed interaction in functional networks and of their reorganization in the recovery after focal brain damage is the domain of functional imaging modalities, such as positron emission tomography and functional MRI (fMRI).

For the analysis of the relationship between disturbed function and altered brain activity, studies can be designed in several ways: measurement at rest, comparing location and extent to deficit and outcome (eventually with follow-up); measurement during activation tasks, comparing changes in activation patterns to functional performance; and measurement at rest and during activation tasks early and later in the course of disease (e.g., after stroke) to demonstrate recruiting and compensatory mechanisms in the functional network responsible for complete or partial recovery of disturbed functions. Only a few studies have been performed by applying this last and most complete design together with extensive testing for the evaluation of the quality of performance finally achieved. A large amount of data has been collected over the past years with functional imaging of changes in activation patterns related to the recovery of disturbed function after stroke [97-103].

\section{Motor and Somatosensory Deficits}

The degree of motor impairment and the potential for motor recovery depends on the site and extent of the lesion, the combination of lesions in cortical areas and fiber tracts, and the involvement of deep gray structures, for example, the basal ganglia, thalamus, and brainstem. Mo- 
tor recovery is not rapid during the first month after stroke and reaches a plateau within 3 months; activities of daily living do not improve beyond 6 months poststroke [104]. The motor recovery plateau can be predicted for individual patients by combining clinical measures with an objective evaluation of descending motor pathway integrity [105]: assessment of shoulder abduction and finger extension is combined with transcranial magnetic stimulation to test the functional integrity of the corticomotor pathway and MRI to detect the extent of damage to the posterior limb of the internal capsule. The used algorithm predicted individual patient's potential to make complete, notable or limited recovery, or no recovery of upper limit functions within 3 months, measured with the Action Research Arm Test [104].

A clear concept of "neuronal plasticity" for motor recovery is still missing: one recent review concluded that "motor recovery after stroke depends on a variety of mechanisms including perilesional motor reorganization, use of motor pathways in subcortical structures, use of collateral pathways in the ipsilateral hemisphere, use of collateral pathways in the contralateral hemisphere, or possibly the development of entirely new motor networks" [99]. A combination of structural and functional imaging methods improves monitoring and predicting hand-motor outcome after stroke: lesions are mapped by T1-weighted imaging: DWI with DTI measures structural connectivity as well as intactness of corticospinal tract, resting stroke fMRI assesses functional connectivity between the different regions of a network; activation fMRI demonstrates regions involved in a function even when alternative pathways are used due to a damage in the primary centers [106], this combination of biomarkers permits the classification of patients into different subgroups with respect to probable outcome, and may help in selecting specific strategies for rehabilitation.

As a consequence, most $\mathrm{AMRI}$ or positron emission tomography studies reported a widespread network activated in both hemispheres with active or passive movements. Changes in the damaged and the undamaged hemispheres are observed, but ipsilateral activation of motor cortex is consistently stronger for the movement of paretic fingers after the recovery from stroke. Movements of the unaffected hand induce activation of the contralateral cerebral cortex as in normal subjects. Additionally, the extent of activation in motor cortex is enlarged, and usually extends to the premotor and insular cortex. This stresses the importance of ipsilateral cortical recruitment in motor recovery; one study demonstrated a direct relationship between activation in the ipsilesion- al motor cortex, supplementary motor cortex and insula, and recovery 1 year after stroke [107]. Task-oriented arm training increased the activation bilaterally in the inferior parietal area, in premotor areas, and in the contralateral sensorimotor cortex, as a substrate of bilateral functional brain reorganization [108]. Newly learned movements involve larger cortical territories, and this effect is dependent on the intensity of rehabilitative training. Another important finding suggests that homotopic areas in the unaffected hemisphere actually inhibit voluntary movement of the paretic hand [109], and thereby impair recovery of function. Recovery of function after stroke also leads to substantial changes in the activity of the proprioceptive systems, reflecting an interhemispheric shift to stimuli associated with recovery [110].

\section{Post-Stroke Aphasia}

Studies of glucose metabolism in aphasia after stroke have shown metabolic disturbances in the ipsilateral hemisphere caused by the lesion and in the contralateral hemisphere caused by functional deactivation (diaschisis; review in [111]). In right-handed individuals with language dominance in the left hemisphere, the left temporo-parietal region, in particular the angular gyrus, supramarginal gyrus, and lateral and transverse superior temporal gyrus (STG) are most frequently and consistently impaired, and the degree of impairment is related to the severity of aphasia. The functional disturbance, as measured by rCMRGlc in speech-relevant brain regions early after stroke, is predictive of the eventual outcome of aphasia. Also, the metabolism in the hemisphere outside the infarct was significantly related to the outcome of poststroke aphasia, a finding supporting previous results of a significant correlation of CMRGlu outside the infarct with functional recovery [112].

Additionally, the functionality of the bihemispheric network has a significant impact on the outcome; although the brain recruits right-hemispheric regions for speech-processing when the left-hemispheric centers are impaired, outcome studies reveal that this strategy is significantly less effective than repair of the speech-relevant network in adults [113]. That the quality of recovery is mainly dependent on undamaged portions of the language network in the left hemisphere and to a lesser extent on homologous right hemisphere areas can be deduced from activation studies in the course after poststroke aphasia [114]. The differences in improvement of speech deficits were reflected in different patterns of activation in the course after stroke: the subcortical and frontal groups improved substantially and activated the 
right inferior frontal gyrus and the right STG at baseline and regained regional left STG activation at follow-up. The temporal group improved only in word comprehension; it activated the left Broca area and supplementary motor areas at baseline and the precentral gyrus bilaterally as well as the right STG at follow-up, but could not reactivate the left STG. These results were confirmed in comparable studies [115-117].

The activation studies in the course of recovery of post-stroke aphasia suggest a hierarchy of various mechanisms for the compensation of the lesion within the functional network:

- Optimal recovery can only be achieved by restoration of the original activation pattern after small brain lesions outside primary centers.

- If primary functional centers are damaged, reduction of collateral inhibition leads to the activation of areas around the lesion (intrahemispheric compensation).

- If the ipsilateral network is severely damaged, reduction of transcallosal inhibition causes the activation of contralateral homotopic areas, which is usually not as efficient as intrahemispheric compensation. In most instances, the disinhibition of homotopic areas contralateral to the lesion impairs the capacity for recovery [118].

\section{Neglect}

Spatial neglect can either spontaneously resolve or persist after stroke - and persisting neglect is associated with poor recovery. A longitudinal fMRI study revealed different signatures: a favorable course of recovery was specifically associated with increased activation in essen- tial functional nodes, when the left prefrontal region replaces the irreversibly damaged ventral attention system and supports spatial performance, driving the preserved ipsilesional dorsal attention system. The strength of functional connectivity between right parietal and left prefrontal region might predict the course of recovery [119].

\section{Conclusions}

Prediction of long-term functional outcomes following ischemic stroke is complex; imaging approaches in both the hyperacute and subacute stages provide added value over clinical prediction variables. In the future, this information, combined with clinical data may be used to guide both acute and rehabilitative therapies, and provide valuable prognostic information. Large databases including both clinical and imaging data may be developed to allow prognostic and therapeutic decision-making to be individualized based on specific clinical factors and individual pathophysiology.

\section{Funding Sources}

Dr. Wolf-Dieter Heiss is supported by the Wolf-Dieter Heiss Foundation at the Max Planck Society.

\section{Disclosures Statement}

The authors have no conflicts of interest to declare.

\section{References}

1 Feigin VL, Krishnamurthi RV, Parmar P, Norrving B, Mensah GA, et al: Update on the Global Burden of Ischemic and Hemorrhagic Stroke in 1990-2013: The GBD 2013 Study. Neuroepidemiology 2015;45: 161-76.

2 Miller EL, Murray L, Richards L, Zorowitz $\mathrm{RD}$, Bakas T, et al: Comprehensive overview of nursing and interdisciplinary rehabilitation care of the stroke patient: a scientific statement from the American Heart Association. Stroke 2010;41:2402-2448.

3 Heiss WD, Rosner G: Functional recovery of cortical neurons as related to degree and duration of ischemia. Ann Neurol 1983;14:294301.

4 Rabinstein A, Rundek T: Prediction of outcome after ischemic stroke: the value of clinical scores. Neurology 2013;80:15-16.
5 Cooray C, Mazya M, Bottai M, Dorado L, Skoda O, et al: External validation of the ASTRAL and DRAGON scores for prediction of functional outcome in stroke. Stroke 2016; 47:1493-1499.

6 Kidwell CS, Jahan R, Gornbein J, Alger JR, Nenov V, et al: A trial of imaging selection and endovascular treatment for ischemic stroke. N Engl J Med 2013;368:914-923.

7 Fisher M, Albers GW: Advanced imaging to extend the therapeutic time window of acute ischemic stroke. Ann Neurol 2013;73:4-9.

8 Mishra NK, Albers GW, Christensen S, Marks M, Hamilton S, et al: Comparison of magnetic resonance imaging mismatch criteria to select patients for endovascular stroke therapy. Stroke 2014;45:1369-1374

9 Menon BK, Campbell BC, Levi C, Goyal M: Role of imaging in current acute ischemic stroke workflow for endovascular therapy. Stroke 2015;46:1453-1461.

10 Kwakkel G, Veerbeek JM, Harmeling-van der Wel BC, van Wegen E, Kollen BJ; Early Prediction of Functional Outcome after Stroke (EPOS) Investigators: Diagnostic accuracy of the Barthel Index for measuring activities of daily living outcome after ischemic hemispheric stroke: does early poststroke timing of assessment matter? Stroke 2011;42:342-346.

11 Johnston KC, Connors AF Jr, Wagner DP, Knaus WA, Wang X, Haley EC Jr: A predictive risk model for outcomes of ischemic stroke. Stroke 2000;31:448-455.

12 Veerbeek JM, Kwakkel G, van Wegen EE, Ket JC, Heymans MW: Early prediction of outcome of activities of daily living after stroke: a systematic review. Stroke 2011;42:1482-1488.
Contribution of Neuro-Imaging for Prediction of Functional Recovery
Cerebrovasc Dis 2017;44:266-276 
13 Konig IR, Ziegler A, Bluhmki E, Hacke W, Bath PM, et al: Predicting long-term outcome after acute ischemic stroke: a simple index works in patients from controlled clinical trials. Stroke 2008;39:1821-1826.

14 Kwakkel G, Veerbeek JM, van Wegen EE, Nijland R, Harmeling-van der Wel BC, et al: Predictive value of the NIHSS for ADL outcome after ischemic hemispheric stroke: does timing of early assessment matter? J Neurol Sci 2010;294:57-61.

15 Muscari A, Puddu GM, Santoro N, Zoli M: A simple scoring system for outcome prediction of ischemic stroke. Acta Neurol Scand 2011; 124:334-342.

16 Ntaios G, Faouzi M, Ferrari J, Lang W, Vemmos K, Michel P: An integer-based score to predict functional outcome in acute ischemic stroke: the ASTRAL score. Neurology 2012; 78:1916-1922.

17 Ntaios G, Gioulekas F, Papavasileiou V, Strbian D, Michel P: ASTRAL, DRAGON and SEDAN scores predict stroke outcome more accurately than physicians. Eur J Neurol 2016; 23:1651-1657.

18 Cao KG, Fu CH, Li HQ, Xin XY, Gao Y: A new prognostic scale for the early prediction of ischemic stroke recovery mainly based on traditional Chinese medicine symptoms and NIHSS score: a retrospective cohort study. BMC Complement Altern Med 2015;15:407.

19 Haselbach D, Renggli A, Carda S, Croquelois A: Determinants of neurological functional recovery potential after stroke in young adults. Cerebrovasc Dis Extra 2014;4:77-83.

20 Lamola G, Bertolucci F, Rossi B, Chisari C: Clinical assessments for predicting functional recovery after stroke. Int J Neurorehabil 2015; 2:174.

21 Kwah LK, Herbert RD: Prediction of walking and arm recovery after stroke: a critical review. Brain Sci 2016;6:53.

22 Glize B, Villain M, Richert L, I DEG, Mazaux $\mathrm{JM}$, et al: Language features in the acute phase of poststroke severe aphasia could predict the outcome. Eur J Phys Rehabil Med 2017;53: 249-255.

23 Lee SY, Lim JY, Kang EK, Han MK, Bae HJ, Paik NJ: Prediction of good functional recovery after stroke based on combined motor and somatosensory evoked potential findings. J Rehabil Med 2010;42:16-20.

24 Arsava EM, Helenius J, Avery R, Sorgun MH, Kim GM, et al: Assessment of the predictive alidity of etiologic stroke classification. JAMA Neurol 2017;74:419-426.

25 Kim B, Winstein C: Can neurological biomarkers of brain impairment be used to predict poststroke motor recovery? A systematic review. Neurorehabil Neural Repair 2017;31: 3-24.

26 Heiss WD, Kidwell CS: Imaging for prediction of functional outcome and assessment of recovery in ischemic stroke. Stroke 2014;45: 1195-1201.

27 Vogt G, Laage R, Shuaib A, Schneider A, Collaboration V: Initial lesion volume is an inde- pendent predictor of clinical stroke outcome at day 90: an analysis of the Virtual International Stroke Trials Archive (VISTA) database. Stroke 2012;43:1266-1272.

28 Borsody M, Warner Gargano J, Reeves M, Jacobs B; MASCOTS Insula-Stroke Substudy Group: Infarction involving the insula and risk of mortality after stroke. Cerebrovasc Dis 2009;27:564-571.

29 Ois A, Cuadrado-Godia E, Solano A, PerichAlsina X, Roquer J: Acute ischemic stroke in anterior choroidal artery territory. J Neurol Sci 2009;281:80-84.

30 Schiemanck SK, Kwakkel G, Post MW, Kappelle LJ, Prevo AJ: Impact of internal capsule lesions on outcome of motor hand function at one year post-stroke. J Rehabil Med 2008;40: 96-101.

31 Battey TW, Karki $\mathrm{M}$, Singhal $\mathrm{AB}$, Wu O, Sadaghiani S, et al: Brain edema predicts outcome after nonlacunar ischemic stroke. Stroke 2014;45:3643-3648.

32 Barber PA, Demchuk AM, Zhang J, Buchan AM: Validity and reliability of a quantitative computed tomography score in predicting outcome of hyperacute stroke before thrombolytic therapy ASPECTS Study Group. Alberta Stroke Programme Early CT Score. Lancet 2000;355:1670-1674.

33 Alexander LD, Pettersen JA, Hopyan JJ, Sahlas DJ, Black SE: Long-term prediction of functional outcome after stroke using the alberta stroke program early computed tomography score in the subacute stage. J Stroke Cerebrovasc Dis 2012;21:737-744.

34 Branco JP, Costa JS, Sargento-Freitas J, Oliveira S, Mendes B, et al: [Neuroimaging and blood biomarkers in functional prognosis after stroke]. Acta Med Port 2016;29:749754.

35 Strbian D, Meretoja A, Ahlhelm FJ, Pitkaniemi J, Lyrer P, et al: Predicting outcome of IV thrombolysis-treated ischemic stroke patients: the DRAGON score. Neurology 2012; 78:427-432.

36 Schiemanck SK, Kwakkel G, Post MW, Prevo AJ: Predictive value of ischemic lesion volume assessed with magnetic resonance imaging for neurological deficits and functional outcome poststroke: a critical review of the literature. Neurorehabil Neural Repair 2006;20:492502.

37 Lindenberg R, Renga V, Zhu LL, Betzler F, Alsop D, Schlaug G: Structural integrity of corticospinal motor fibers predicts motor impairment in chronic stroke. Neurology 2010; 74:280-287.

38 Dawes H, Enzinger C, Johansen-Berg H, Bogdanovic M, Guy C, et al: Walking performance and its recovery in chronic stroke in relation to extent of lesion overlap with the descending motor tract. Exp Brain Res 2008; 186:325-333.

39 Kissela B, Lindsell CJ, Kleindorfer D, Alwell $\mathrm{K}$, Moomaw CJ, et al: Clinical prediction of functional outcome after ischemic stroke: the surprising importance of periventricular white matter disease and race. Stroke 2009;40: 530-536.

40 Kidwell CS, Chalela JA, Saver JL, Starkman S, Hill MD, et al: Comparison of MRI and CT for detection of acute intracerebral hemorrhage. JAMA 2004;292:1823-1830.

41 Strbian D, Sairanen T, Meretoja A, Pitkaniemi J, Putaala J, et al: Patient outcomes from symptomatic intracerebral hemorrhage after stroke thrombolysis. Neurology 2011;77:341348

42 Park JH, Ko Y, Kim WJ, Jang MS, Yang MH et al: Is asymptomatic hemorrhagic transformation really innocuous? Neurology 2012;78: 421-426.

43 Thijs VN, Lansberg MG, Beaulieu C, Marks MP, Moseley ME, Albers GW: Is early ischemic lesion volume on diffusion-weighted imaging an independent predictor of stroke outcome? A multivariable analysis. Stroke 2000;31:2597-2602.

44 Hand PJ, Wardlaw JM, Rivers CS, Armitage PA, Bastin ME, et al: MR diffusion-weighted imaging and outcome prediction after ischemic stroke. Neurology 2006;66:1159-1163.

45 Johnston KC, Wagner DP, Wang XQ, Newman GC, Thijs V, et al: Validation of an acute ischemic stroke model: does diffusionweighted imaging lesion volume offer a clinically significant improvement in prediction of outcome? Stroke 2007;38:1820-1825.

46 Barrett KM, Ding YH, Wagner DP, Kallmes $\mathrm{DF}$, Johnston KC, Investigators A: Change in diffusion-weighted imaging infarct volume predicts neurologic outcome at 90 days: results of the acute stroke accurate prediction (ASAP) trial serial imaging substudy. Stroke 2009;40:2422-2427.

47 Phan TG, Chen J, Donnan G, Srikanth V, Wood A, Reutens DC: Development of a new tool to correlate stroke outcome with infarct topography: a proof-of-concept study. Neuroimage 2010;49:127-133.

48 Kidwell CS, Szpakowski N, Stidd R, Alger JR: Development of a large scale predictive atlas of clinical outcome in acute ischemic stroke. Stroke 2012;43:A3655.

49 Jang SH: Prediction of motor outcome for hemiparetic stroke patients using diffusion tensor imaging: a review. NeuroRehabilitation 2010;27:367-372.

50 Bigourdan A, Munsch F, Coupe P, Guttmann CR, Sagnier S, et al: Early Fiber number ratio is a surrogate of corticospinal tract integrity and predicts motor recovery after stroke. Stroke 2016;47:1053-1059.

51 Kim KH, Kim YH, Kim MS, Park CH, Lee A, Chang WH:Prediction of motor recovery using diffusion tensor tyractography in supratentorial stroke patients with severe motor involvement. Ann Rehabil Med 2015;39:570-576.

52 Cho SH, Kim DG, Kim DS, Kim YH, Lee CH, Jang SH: Motor outcome according to the integrity of the corticospinal tract determined by diffusion tensor tractography in the early stage of corona radiata infarct. Neurosci Lett 2007;426:123-127. 
53 Radlinska B, Ghinani S, Leppert IR, Minuk J, Pike GB, Thiel A: Diffusion tensor imaging, permanent pyramidal tract damage, and outcome in subcortical stroke. Neurology 2010; 75:1048-1054.

54 Liang Z, Zeng J, Zhang C, Liu S, Ling X, et al: Longitudinal investigations on the anterograde and retrograde degeneration in the pyramidal tract following pontine infarction with diffusion tensor imaging. Cerebrovasc Dis 2008;25:209-216.

55 Puig J, Pedraza S, Blasco G, Daunis IEJ, Prados F, et al: Acute damage to the posterior limb of the internal capsule on diffusion tensor tractography as an early imaging predictor of motor outcome after stroke. AJNR Am J Neuroradiol 2011;32:857-863.

56 Kumar P, Kathuria P, Nair P, Prasad K: Prediction of upper limb motor recovery after subacute ischemic stroke using diffusion tensor imaging: a systematic review and metaanalysis. J Stroke 2016;18:50-59.

57 Lindenberg R, Zhu LL, Ruber T, Schlaug G: Predicting functional motor potential in chronic stroke patients using diffusion tensor imaging. Hum Brain Mapp 2012;33:10401051.

58 Riley JD, Le V, Der-Yeghiaian L, See J, Newton JM, et al: Anatomy of stroke injury predicts gains from therapy. Stroke 2011;42:421426.

59 Song J, Nair VA, Young BM, Walton LM, Nigogosyan Z, et al: DTI measures track and predict motor function outcomes in stroke rehabilitation utilizing BCI technology. Front Hum Neurosci 2015;9:195.

60 Breier JI, Hasan KM, Zhang W, Men D, Papanicolaou AC: Language dysfunction after stroke and damage to white matter tracts evaluated using diffusion tensor imaging. AJNR Am J Neuroradiol 2008;29:483-487.

61 Kim SH, Jang SH: Prediction of aphasia outcome using diffusion tensor tractography for arcuate fasciculus in stroke. AJNR Am J Neuroradiol 2013;34:785-790.

62 Stinear CM, Ward NS: How useful is imaging in predicting outcomes in stroke rehabilitation? Int J Stroke 2013;8:33-37.

63 Lau AY, Wong KS, Lev M, Furie K, Smith W, Kim AS: Burden of intracranial steno-occlusive lesions on initial computed tomography angiography predicts poor outcome in patients with acute stroke. Stroke 2013;44:1310-1316.

64 Lima FO, Furie KL, Silva GS, Lev MH, Camargo EC, et al: Prognosis of untreated strokes due to anterior circulation proximal intracranial arterial occlusions detected by use of computed tomography angiography. JAMA Neurol 2014;71:151-157.

65 Fischer U, Arnold M, Nedeltchev K, Brekenfeld C, Ballinari P, et al: NIHSS score and arteriographic findings in acute ischemic stroke. Stroke 2005;36:2121-2125.

66 Burke MJ, Vergouwen MD, Fang J, Swartz RH, Kapral MK, et al: Short-term outcomes after symptomatic internal carotid artery occlusion. Stroke 2011;42:2419-2424.
67 Smith WS, Lev MH, English JD, Camargo EC, Chou M, et al: Significance of large vessel intracranial occlusion causing acute ischemic stroke and TIA. Stroke 2009; 40:3834-3840.

68 Gonzalez RG, Lev MH, Goldmacher GV, Smith WS, Payabvash S, et al: Improved outcome prediction using CT angiography in addition to standard ischemic stroke assessment: results from the STOPStroke study. PloS One 2012;7:e30352.

69 Mortimer AM, Simpson E, Bradley MD, Renowden SA: Computed tomography angiography in hyperacute ischemic stroke: prognostic implications and role in decision-making. Stroke 2013;44:1480-1488.

70 Kucinski T, Koch C, Eckert B, Becker V, Kromer H, et al: Collateral circulation is an independent radiological predictor of outcome after thrombolysis in acute ischaemic stroke. Neuroradiology 2003;45:11-18.

71 Bang OY, Saver JL, Kim SJ, Kim GM, Chung CS, et al: Collateral flow predicts response to endovascular therapy for acute ischemic stroke. Stroke 2011;42:693-699.

72 Maas MB, Lev MH, Ay H, Singhal AB, Greer $\mathrm{DM}$, et al: Collateral vessels on CT angiography predict outcome in acute ischemic stroke. Stroke 2009; 40:3001-3005.

73 Lima FO, Furie KL, Silva GS, Lev MH, Camargo EC, et al: The pattern of leptomeningeal collaterals on CT angiography is a strong predictor of long-term functional outcome in stroke patients with large vessel intracranial occlusion. Stroke 2010;41:23162322

74 Tan BY, Kong WY, Ngiam JN, Teoh HL, Sharma VK, Yeo LL: The role of topographic collaterals in predicting functional outcome after thrombolysis in anterior circulation ischemic stroke. J Neuroimaging 2017;27: 217-220.

75 Kane I, Carpenter T, Chappell F, Rivers C, Armitage $\mathrm{P}$, et al: Comparison of 10 different magnetic resonance perfusion imaging processing methods in acute ischemic stroke: effect on lesion size, proportion of patients with diffusion/perfusion mismatch, clinical scores, and radiologic outcomes. Stroke 2007;38: 3158-3164.

76 Bivard A, Spratt N, Levi C, Parsons M: Perfusion computer tomography: imaging and clinical validation in acute ischaemic stroke. Brain 2011;134:3408-3416.

77 Heiss WD, Zeiler K, Havelec L: Hirndurchblutung und soziale Prognose nach ischämischem zerebralem Insult. Dtsch Med Wschr 1978;103:597-602.

78 Giubilei F, Lenzi GL, Di Piero V, Pozzilli C, Pantano P, et al: Predictive value of brain perfusion single-photon emission computed tomography in acute ischemic stroke. Stroke 1990;21:895-900

79 Parsons MW, Pepper EM, Chan V, Siddique S, Rajaratnam S, et al: Perfusion computed tomography: prediction of final infarct extent and stroke outcome. Ann Neurol 2005;58: 672-679.
80 Psychogios MN, Schramm P, Frolich AM, Kallenberg K, Wasser K, et al: Alberta stroke program early CT scale evaluation of multimodal computed tomography in predicting clinical outcomes of stroke patients treated with aspiration thrombectomy. Stroke 2013; 44:2188-2193.

81 Payabvash S, Souza LC, Kamalian S, Wang Y, Passanese J, et al; Location-weighted CTP analysis predicts early motor improvement in stroke: a preliminary study. Neurology 2012; 78:1853-1859.

82 Payabvash S, Kamalian S, Fung S, Wang Y, Passanese J, et al: Predicting language improvement in acute stroke patients presenting with aphasia: a multivariate logistic model using location-weighted atlas-based analysis of admission CT perfusion scans. AJNR Am J Neuroradiol 2010;31:1661-1668.

83 Yoo AJ, Barak ER, Copen WA, Kamalian S, Gharai LR, et al: Combining acute diffusionweighted imaging and mean transmit time lesion volumes with National Institutes of Health Stroke Scale Score improves the prediction of acute stroke outcome. Stroke 2010;41:1728-1735.

84 Schaefer PW, Pulli B, Copen WA, Hirsch JA, Leslie-Mazwi T, et al: Combining MRI with NIHSS thresholds to predict outcome in acute ischemic stroke: value for patient selection. AJNR Am J Neuroradiol 2015;36:259-264.

85 Padroni M, Bernardoni A, Tamborino C, Roversi G, Borrelli M, et al: Cerebral blood volume ASPECTS is the best predictor of clinical outcome in acute ischemic stroke: a retrospective, combined semi-quantitative and quantitative assessment. PloS One 2016; 11:e0147910.

86 Tsogkas I, Knauth M, Schregel K, Behme D, Wasser K, et al: Added value of CT perfusion compared to CT angiography in predicting clinical outcomes of stroke patients treated with mechanical thrombectomy. Eur Radiol 2016;26:4213-4219.

87 Heiss WD, Weber OZ: Uncertainties in the assessment of cortical flow by perfusionweighted MRI in acute stroke. Cerebrovasc Dis 2011;32:194-195.

88 Wahlgren N, Ahmed N, Eriksson N, Aichner F, Bluhmki E, et al: Multivariable analysis of outcome predictors and adjustment of main outcome results to baseline data profile in randomized controlledtrials: Safe Implementation of Thrombolysis in Stroke-MOnitoring STudy (SITS-MOST). Stroke 2008;39:33163322.

89 Strbian D, Seiffge DJ, Breuer L, Numminen $\mathrm{H}$, Michel $\mathrm{P}$, et al: Validation of the DRAGON score in 12 stroke centers in anterior and posterior circulation. Stroke 2013;44:27182721.

90 Turc G, Apoil M, Naggara O, Calvet D, Lamy $C$, et al: Magnetic resonance imagingDRAGON score: 3-month outcome prediction after intravenous thrombolysis for anterior circulation stroke. Stroke 2013;44:13231328.
Contribution of Neuro-Imaging for

Prediction of Functional Recovery
Cerebrovasc Dis 2017;44:266-276

DOI: $10.1159 / 000479594$ 
91 Vora NA, Shook SJ, Schumacher HC, Tievsky AL, Albers GW, et al: A 5-item scale to predict stroke outcome after cortical middle cerebral artery territory infarction: validation from results of the Diffusion and Perfusion Imaging Evaluation for Understanding Stroke Evolution (DEFUSE) Study. Stroke 2011;42:645-649.

92 Davis SM, Donnan GA, Parsons MW, Levi C, Butcher KS, et al: EPITHET investigators: Effects of alteplase beyond $3 \mathrm{~h}$ after stroke in the Echoplanar Imaging Thrombolytic Evaluation Trial (EPITHET): a placebo-controlled randomised trial. Lancet Neurol 2008;7:299309.

93 Albers GW, Thijs VN, Wechsler L, Kemp S, Schlaug G, et al: Magnetic resonance imaging profiles predict clinical response to early reperfusion: the diffusion and perfusion imaging evaluation for understanding stroke evolution (DEFUSE) study. Ann Neurol 2006;60:508-517.

94 Lansberg MG, Straka M, Kemp S, Mlynash $\mathrm{M}$, Wechsler LR, et al: MRI profile and response to endovascular reperfusion after stroke (DEFUSE 2): a prospective cohort study. Lancet Neurol 2012;11:860-867.

95 Parsons M, Spratt N, Bivard A, Campbell B, Chung $\mathrm{K}$, et al: A randomized trial of tenecteplase versus alteplase for acute ischemic stroke. N Engl J Med 2012;366:10991107.

96 Sarraj A, Albright K, Barreto AD, Boehme $\mathrm{AK}$, Sitton CW, et al: Optimizing prediction scores for poor outcome after intra-arterial therapy in anterior circulation acute ischemic stroke. Stroke 2013;44:3324-3330.

97 Herholz K, Heiss WD: Functional imaging correlates of recovery after stroke in humans. J Cereb Blood Flow Metab 2000;20: 1619-1631.

98 Rijntjes M, Weiller C: Recovery of motor and language abilities after stroke: the contribution of functional imaging. Progress in Neurobiol 2002;66:109-122.

99 Thirumala P, Hier DB, Patel P: Motor recovery after stroke: Lessons from functional brain imaging. Neurol Res 2002;24:453-458.

100 Rossini PM, Calautti C, Pauri F, Baron JC: Post-stroke plastic reorganisation in the adult brain. Lancet Neurol 2003;2:493-502.

101 Ward NS: Future perspectives in functional neuroimaging in stroke recovery. Eura Medicophys 2007;43:285-294.
102 Cramer SC: Repairing the human brain after stroke: I. Mechanisms of spontaneous recovery. Ann Neurol 2008;63:272-287.

103 Eliassen JC, Boespflug EL, Lamy M, Allendorfer J, Chu WJ, Szaflarski JP: Brain-mapping techniques for evaluating poststroke recovery and rehabilitation: a review. Top Stroke Rehabil 2008;15:427-450.

104 Stinear CM, Byblow WD: Predicting and accelerating motor recovery after stroke. Curr Opin Neurol 2014;27:624-630.

105 Stinear CM, Barber PA, Petoe M, Anwar S, Byblow WD: The PREP algorithm predicts potential for upper limb recovery after stroke. Brain 2012;135:2527-2535.

106 Horn U, Grothe M, Lotze M: MRI biomarkers for hand-motor outcome prediction and therapy monitoring following stroke. Neural Plast 2016;2016:9265621.

107 Loubinoux I, Dechaumont-Palacin S, Castel-Lacanal E, De Boissezon X, Marque P, et al: Prognostic value of FMRI in recovery of hand function in subcortical stroke patients. Cereb Cortex 2007;17:29802987.

108 Nelles G, Jentzen W, Jueptner M, Mller S, Diener HC: Arm training induced brain plasticity in stroke studied with serial positron emission tomography. Neuroimage 2001;13:1146-1154.

109 Murase N, Duque J, Mazzocchio R, Cohen LG: Influence of interhemispheric interactions on motor function in chronic stroke. Ann Neurol 2004;55:400-409.

110 Thiel A, Aleksic B, Klein JC, Rudolf J, Heiss WD: Changes in proprioceptive systems activity during recovery from post-stroke hemiparesis. J Rehabil Med 2007;39:520525.

111 Heiss WD, Thiel A, Kessler J, Herholz K: Disturbance and recovery of language function: correlates in PET activation studies. Neuroimage 2003;1:S42-S49.

112 Heiss WD, Emunds HG, Herholz K: Cerebral glucose metabolism as a predictor of rehabilitation after ischemic stroke. Stroke 1993;24:1784-1788.

113 Heiss WD, Kessler J, Thiel A, Ghaemi M, Karbe H: Differential capacity of left and right hemispheric areas for compensation of poststroke aphasia. Ann Neurol 1999;45: 430-438.

114 Heiss WD, Kessler J, Thiel A, Ghaemi M, Karbe H: Differential capacity of left and right hemispheric areas for compensation of poststroke aphasia. Ann Neurol 1999;45: 430-438.

115 Cao Y, Vikingstad EM, George KP, Johnson AF, Welch KM: Cortical language activation in stroke patients recovering from aphasia with functional MRI. Stroke 1999;30:23312340.

116 Warburton E, Price CJ, Swinburn K, Wise RJ; Mechanisms of recovery from aphasia: evidence from positron emission tomography studies. J Neurol Neurosurg Psychiatry 1999;66:155-161.

117 Saur D, Buchert R, Knab R, Weiller C, Rother J: Iomazenil-single-photon emission computed tomography reveals selective neuronal loss in magnetic resonancedefined mismatch areas. Stroke 2006;37: 2713-2719.

118 Heiss WD, Thiel A: Basic Principles of rTMS in Aphasia Treatment after Stroke. In Therapeutic rTMS in Neurology: Principles, Evidence, and Practice Recommendations, ed. Ts Platz, Springer, 2016.

119 Umarova RM, Nitschke K, Kaller CP, Kloppel S, Beume L, et al: Predictors and signatures of recovery from neglect in acute stroke. Ann Neurol 2016;79:673-686.

120 Weimar C, Konig IR, Kraywinkel K, Ziegler A, Diener HC; German Stroke Study Collaboratio: Age and National Institutes of Health Stroke Scale Score within 6 hours after onset are accurate predictors of outcome after cerebral ischemia: development and external validation of prognostic models. Stroke 2004;35:158-162.

121 Granger CV, Dewis LS, Peters NC, Sherwood CC, Barrett JE: Stroke rehabilitation: analysis of repeated Barthel index measures. Arch Phys Med Rehabil 1979;60:1417.

122 Alexander MP: Stroke rehabilitation outcome. A potential use of predictive variables to establish levels of care. Stroke 1994;25: 128-134.

123 Reid JM, Gubitz GJ, Dai D, Kydd D, Eskes $G$, et al: Predicting functional outcome after stroke by modelling baseline clinical and CT variables. Age Ageing 2010;39:360366.

124 Tilling K, Sterne JA, Rudd AG, Glass TA, Wityk RJ, Wolfe CD: A new method for predicting recovery after stroke. Stroke 2001;32: 2867-2873. 